\section{CONTEMPORARY PHYSICS}

\author{
By Prof. E. N. DA C. ANDRADE, F.R.S. \\ University College, London
}

$I_{\mathrm{r}}^{\mathrm{T}}$

must, of course, be clearly understood that the following brief notes do not profess to mention, even by name, every important line of research in physics that is going on in the U.S.S.R.; they cannot even hope to mention everything of interest that I personally saw during our recent visit as guests of the Academy of Sciences. They must be taken, rather, as general impressions left by the varied activities of the laboratories in which we were so warmly welcomed by our Russian colleagues, who were anxious to let us see the progress that they were making in the world of research, but equally anxious that we should not miss any of the receptions or festivities so bountifully prepared.

The leader of Russian physics is Academician A. F. Joffe, vice-president of the Academy of Sciences, who first began in 1903, in conjunction with Röntgen, the work on crystals which, in one form or another, has always occupied his attention. His book on the physics of crystals is known to most English physicists. $\mathrm{He}$ is now sixty-seven, but in full vigour and actively controlling a great variety of research, as well as pursuing his own investigations-a comment on the British system of fixing sixty-five as the retiring age in most scientific posts. In the Physico-Technical Institute at Leningrad, which is under his immediate direction, work is mainly concentrated on three general subjects, namely, semi-conductors, intermolecular forces in polymers and nuclear problems. It must be understood that the Institute was transferred to Kazan during the siege of Leningrad and did not return until March this year : it says much for the vigour of the laboratory that work is already in full swing on the first two subjects named, and it is not surprising that the nuclear work is only just beginning. The spectral distribution of particles emitted by the nucleus is the general theme that is to be undertaken.

Work on semi-conductors has for many years been a favourite subject with Joffe, and arose naturally out of his interest in the real structure of crystals. The investigations have been much influenced by a theory of the rectifying effect put forward some years ago by Joffe and Frenkel ; incidentally, Frenkel's theoretical work pervades many branches of presentday physics in the U.S.S.R., and I much regret that a change in our general plans interfered with an appointment for discussion which we had made. Semi-conductors can show what may be for brevity termed both electronic and ionic conductivity, or positive and negative conductivity. It has been demonstrated in Joffe's laboratory that the same substance, for example, lead sulphide or thallium sulphide, can be produced with either high or low conductivity and with either positive or negative conductivity, according to the amount and the nature of small admixtures of certain substances. Excess of sulphur gives positive conductivity, excess of metal, negative. Active work is proceeding on many lines, both on the fundamental physical properties of semiconductors, which throw light on the mechanism of conduction in solids, and on their practical use for industrial rectifiers. This combination of pure and industrial research in the same institute is typical of the U.S.S.R. system. Closely connected with the work on semi-conductors is that on photocells. The thallium sulphide cell developed under Joffe gives up to 8 milliamp. per lumen. In many of his own researches Joffe enjoys the collaboration of the charming Madame Joffe, who acted as our hostess on more than one occasion.

Work on dielectrics is also proceeding. For example, the dielectric properties of hexafluoride of sulphur, which has an electrical strength two and a half times that of air, are under investigation.

As regards the work on polymers, much is being done in the way of cross-linking the molecules of cellulose by acting on the hydroxyl groups, a process somewhat analogous to the vulcanization of rubber. In this way the fibres can be made either elastic or brittle, and filter papers have been prepared which retain their strength in water.

All kinds of physical work in other laboratories is under Joffe's general direction. He has, for example, taken a leading part in organizing work on the measurement of soil temperature by an ingenious new method and on the measurement of the tem. perature of leaves, which has led to important practical results in agriculture.

Academician P. Kapitza (or Kapitsa, as his name is usually transliterated by the Russians) has a splendid modern Institute for Physical Problems, built in 1935-36. The most striking work proceeding here is, on the pure side, that on the suporfluidity of helium II, discovered independently in 1937 by Kapitza in Moscow and by Allen and Misener in Cambridge, and, on the applied side, that on the liquefaction of air by Kapitza's turbine liquefier and on the preparation of liquid oxygen from the liquid air by a new type of apparatus for fractional distillation. Kapitza has recently been studying heat transfer in helium II in its relation to superfluidity and has found that the supposed abnormal heat conductivity is really a manifestation of its abnormally low viscosity. Connected with this is the existence of a counter current in the liquid. There are also two possible velocities of sound in helium II, the existence of a 'second sound' having been recently shown experimentally by Peshkov. These most curious properties of liquid helium have been explained in a remarkable theoretical paper by Landau. Work in this field is being actively continued. As regards the production of liquid oxygen on an industrial scale, the turbine liquefier, described just before the outbreak of the War, has the great advantage that it can be started up very rapidly and that it is much smaller and easier to maintain than the conventional machine. One machine is said to have run non-stop for four thousand hours. The methods of producing liquid oxygen developed in Kapitza's institute are being installed in factories all over the U.S.S.R.

There are various special institutes in which physics enters largely, although not exclusively, into the work. The Optical Institute is probably the largest, employing in all about five thousand workers; an account of one of the most interesting developments there, Maksutov's meniscus telescope, was given in Nature of June 30, p. 798. The Institute for Theoretical Geophysics deals with geoprospecting by electrical, seismic and magnetic methods and by a new thermal method; with atmospheric electricity and the transparency of the atmosphere; with ionospheric phenomena; and with the light of the night sky, on which Khvostikov has worked extensively. Some of the work in Academician Semenov's Institute of Chemical Physics, housed in a converted palace, is of 
a very physical nature, as, for example, a special method of measuring the abnormal viscosity which certain liquids have in layers immediately adjacent to a solid boundary : this method consists in blowing off the liquid with a controlled current of air and measuring the dimensions of the resulting wedgeshaped film by interference methods.

Academician Sergei Vavilov, director of the Lebedev Physics Institute, who is in charge of research at the Optical Institute, is keenly interested in the history of physics : he published a Life of Newton in 1943, in connexion with the tercentenary celebrations of Newton's birth, and edited a collection of papers on various aspects of Newton's work, to which he contributed a chapter on aspects of Newton's optical work. He also contributed a study of Galileo's work on optics to a recently published Russian work on Galileo. He tells me that he is now engaged on a complete Russian translation of Newton's "Lectiones Opticæ": the English translation which appeared in 1728 is of the first part only.

Reference must be made to the work of Rehbinder on the effect of surface-active substances for facilitating the working of metals, and particularly to some very interesting recent work on the effect of surface-active films in decreasing the resistance to mechanical flow of single crystals of metals. These films send up the electrical resistance appreciably, indicating that they penetrate deep into interstices in the metal.

If it does nothing else, this brief account may give some idea of the variety of the work in pure and applied physies that is proceeding with vigour in the U.S.S.R. It cannot, however, convey the spirit of cordiality and co-operation in which we were everywhere received, which has left a deep and abiding impression in our minds.

\section{ARCH/EOLOGY AND ANTHROPOLOGY By PROF. V. GORDON CHILDE University of Edinburgh}

$\mathrm{A}^{\mathrm{H}}$ RCHEOLOGY and anthropology are classed as sciences in the U.S.S.R. and with other social seiences stand under the $x$ gis of Akademiya Nauk as much as the natural sciences. Hence during the War, archæologists and anthropologists have been 'reserved' like geologists or physicists. However, several very promising men of the younger generation, notably E. Krichevskiy, perished during the siege of Leningrad, and the gaps left by such casualties will take time to fill. At the same time, archæological research naturally suffered worse dislocation since 1941 than that in sciences more directly related to the war effort.

Museum collections had inevitably to be packed up. But in Moscow the State Historical Museum is already re-installed fully and open to the public; in the University of Moscow, despite considerable damage sustained by the building, the collections of the Anthropological Institute are actively in course of reinstatement, and I was able to handle the skull of the Neanderthal boy from Teshik Tash in Uzbe. kistan. In Leningrad the treasures of the Hermitage were not due to come back from hiding places in the Urals until August ; in the Ethnographic Museum of the Academy an impressive exhibition illustrated by choice specimens, hastily unpacked and specially arranged by the staff, anthropometric, archæological and ethnographic work of the last ten years. Terrible damage, on the other hand, has been done to the famous collections in Kiev and in many local museums in the Ukraine and the Caucasus, where much unpublished material has been destroyed or dispersed by the invaders. A fine Hellenistic sarcophagus from the Taman Peninsula, abandoned by the Nazis, has just been restored in Moscow from the fragments to which the enemy had deliberately reduced it.

Field-work and the study of the collected material were never entirely suspended during the War. The exhibition in Leningrad and a special session of the Institute for the History of Material Culture (IIMK) held in Moscow introduced the Academy's guests to the results of operations so recent that no published accounts have reached western Europe. In Transcaucasia, Zamiatnin's surveys of Abkhasia, initiated in 1934, have brought to light the first undoubted Acheulean hand-axes from the territories of the Union as well as flake industries of Clactonian and Mousterian types, all illustrated at Leningrad. Tolstov described before the Institute the main results of the expedition under his direction in the ancient Khorasmia (the lower Oxus valley). The earliest settlements discovered belong to hunterfishers whose ceramic remains show analogies with the chalcolithic cultures of western Siberia and the Russian steppes. To the later Bronze Age belong some very schematic rock-engravings, while during the first millennium B.c. an advanced urban civilization, based on irrigation, developed. From the fourth century A.D. cities began to give place to isolated eastles and fortified manors. At the same session Passek described her first explorations at Vladimirovka in the Bug basin, a large village of the 'Painted Pottery Culture' often called Tripolyanexcavations abruptly terminated by the Nazi invasion in 1941. Her survey has revealed there the existence of half-subterranean dwellings (zemlianki) as well as no less than five rings of ploshchadki. The 'areas' of burnt clay designated by the latter term turn out to be the floors of rectangular houses, which have been baked by fires specially kindled upon them and on which are found clay ovens, ritual pedestals, querns and groups of vases. These observations confirm and supplement the conclusions drawn from the excavations at Kolomishchina on the middle Dnieper, published with full documentation (in Ukrainian with French and Russian summaries) in Tripil's'ka Kul'tura (Kiev, 1941).

In physical anthropology the outstanding exhibits in Leningrad were the reconstructions from the skeletal material of faces and busts ranging from the Neanderthaler of Teshik-Tash to historical personages like Timur and Yaroslav Mudryy̆, executed by the sculptor anthropologist, Gerasimov, and exhibited with a convincing explanation of his methods. At the same time an anthropometric study is in progress on the abundant skeletal remains from the Fatyanovo cemetery of Balonovo near Kazan, while Debetz is in eastern Siberia continuing his anthropometric survey. Similarly Okladnikov, being again in Yakutia, could give no account of his interesting archæological and ethnographic discoveries along the Lena. For the same reason, we must await publication to hear of Grakova's latest finds in Fatyanovo cemeteries and her geographical and chronological classification of Fatyanovo relics, which is already prepared for publication.

Publication of arch $x$ ological and anthropological periodicals in Moscow and Leningrad has been sus- 